\title{
A INEFICÁCIA DE MEDIDAS PROTETIVAS DE URGÊNCIA PREVISTAS NA LEI MARIA DA PENHA, LEI № 11.340/06
}

\section{ARTIGO ORIGINAL}

SANTOS, Estephanie Dias dos ${ }^{1}$

SANTOS, Estephanie Dias dos. A ineficácia de medidas protetivas de urgência previstas na lei maria da penha, lei no 11.340/06. Revista Científica Multidisciplinar Núcleo do Conhecimento. Ano. 06, Ed. 12, Vol. 08, pp. 127-147. Dezembro de 2021. ISSN: 2448-0959, Link

de acesso: https://www.nucleodoconhecimento.com.br/lei/medidas-protetivas, DOI: 10.32749/nucleodoconhecimento.com.br/lei/medidas-protetivas

\section{RESUMO}

A lei Maria da Penha constitui um avanço no combate à violência contra a mulher. Esta surgiu tardiamente no Brasil, pois durante a história do país, a violência doméstica era pouco punida, tendendo a gerar uma naturalização do fenômeno na sociedade, principalmente em alguns contextos sociais acometidos por grande desigualdade social. As medidas protetivas de urgência são fundamentais para proteger a mulher agredida. Neste artigo, é feita uma análise dessas medidas buscando responder ao seguinte problema: em que sentido as medidas protetivas de urgência são ineficazes? Parte-se de uma pesquisa bibliográfica realizada, em grande parte, em bancos de dados online, onde foram consultadas dissertações e teses, assim como artigos científicos e livros. Constata-se que a ineficácia não está necessariamente nas medidas protetivas de urgência, mas em sua execução. Ocorre que a execução das medidas supracitadas desconsidera o fato de que as características culturais e institucionais presentes nas famílias, e que causam a violência doméstica exercida por homens contra a mulher, não estão presentes nas delegacias, na política, no judiciário e no ministério público. Na medida em que as

\footnotetext{
${ }^{1}$ Bacharel em Direito.
}

RC: 103753

Disponível em: https://www.nucleodoconhecimento.com.br/lei/medidas-protetivas 
causas da violência doméstica estão associadas a mecanismos socioculturais de dominação masculina, relações entre classes sociais e mecanismos de poder, é verossímil a conclusão de que as instituições do Estado, que aplicam as medidas protetivas, precisam passar por aprendizados sociais importantes para superar uma determinada cultura que naturaliza a violência contra a mulher. A ideia de uma delegacia da mulher é um exemplo de atitude por parte do Estado que observa esse fato, e mais atitudes assim, mediadas pelos mesmos pressupostos que sustentam a necessidade desse tipo de delegacia, são a solução para atingir a eficácia das medidas protetivas de urgência.

Palavras-chave: Violência, Mulher, Lei Maria da Penha, Machismo.

\section{INTRODUÇÃO}

Este artigo trata das medidas protetivas de urgência para proteção da mulher em relação ao agressor. Busca delimitar a ineficácia dessas medidas de urgência postas pela Lei Maria da Penha.

A pesquisa trata de uma análise ampla do que acarreta a ineficiência das medidas protetivas de urgência, desde influências internas, externas, envolvendo contextos históricos, sociais e legais e suas consequências ao meio discutido, em relação a ausência de mecanismos que assegurem a efetividade e segurança da mulher em seu momento de violência, outrossim, da falha no desempenho de uma quebra de paradigmas a respeito do machismo e padrões estabelecidos pela sociedade, o que prejudica também nas ações do Estado na diminuição necessária dessa violência, desde física ou psicológica, além de parecer omissa em certos aspectos, como o "tabu" em relação a sexualidade.

Devido à dificuldade para descontruir a cultura do machismo para mais efetivo à Lei Maria da Penha, esse estudo se justifica através da análise dos pontos que tornam a medida protetiva ineficaz em sua prática, com a vantagem em obter soluções para essa grande problemática.

RC: 103753

Disponível em: https://www.nucleodoconhecimento.com.br/lei/medidas-protetivas 
Dessa forma, em face desse contexto supracitado, configura-se a seguinte questão: mesmo após a Lei Maria da Penha, a violência contra a mulher tem ainda alto grau de ocorrência o que sugere algum grau de ineficácia. Em face disso, em que sentido medidas protetivas de urgência previstas na Lei Maria da Penha são ineficazes para combater a violência contra a mulher?

Por conseguinte, os objetivos são de demonstrar os motivos das falhas e possíveis meios de reversão do quadro a respeito das medidas protetivas de urgência contra crimes de violência ao gênero feminino no ambiente familiar.

Vale lembrar, que a discussão que segue parte de pesquisa bibliográfica, que operou a partir de buscas em banco de dados de artigos científicos, dissertações e teses online. Auxiliar a isso, também foram usados livros de doutrinadores que elaboraram análises pertinentes para responder à questão desta pesquisa.

Acerca dessa problemática, observa-se que a violência contra a mulher não é algo contemporâneo. Já que, desde os primórdios o gênero feminino era caracterizado como um ser inferior e ainda hoje é corriqueiro este tipo de pensamento em determinados indivíduos. Por consequência, há a discriminação e preconceito instituídos por suas "bolhas sociais".

É possível observar, que quando a lei foi promulgada houve alegações de ser inconstitucional, por acreditarem que "feriam" o contexto de todos serem iguais perante a lei, no entanto, não foi analisado que a violência da mulher é algo real e que muitas vezes é passado despercebido, logo, sendo de necessário debate.

Portanto, é de necessária relevância relatar as medidas protetivas de urgência, em sua legalidade e prática, destacando os artigos da Lei. 11.340/06 com suas medidas de proteção e demonstrar suas tribulações para possíveis soluções.

RC: 103753

Disponível em: https://www.nucleodoconhecimento.com.br/lei/medidas-protetivas 


\section{DESENVOLVIMENTO}

\subsection{A VIOLÊNCIA CONTRA A MULHER NO BRASIL}

Quando o Estado resolve tutelar a diversidade cultural, isso pressupõe o processo de coexistência social com todo tipo de diversidade, o que envolve também a sexual. Envolve, ainda, dar uma atitude recursiva do que entendemos ou interpretamos como economia, como lei, sobre biologia, gênero, orientações sexuais, raça, etnia, crença religiosa. O escopo da discussão que o Estado empreende inclui vários aspectos da vida social e da sociabilidade que contextualizam o fenômeno do preconceito e da violência resultante de discriminação (SIMMEL, 2006).

O preconceito, que pode ser definido como atitudes desfavoráveis em relação a certos grupos sociais, foi identificado nas práticas de dominância adotadas por grupos e classes sociais. Bem como discriminação, que pode ser definida como aquela violência direcionada a grupos específicos. O preconceito tende a provocar isolamento social e estabelecer limites em áreas simbólicas e materiais que alienam certos grupos (SANTOS, 2017). Isto porque o preconceito e a discriminação se baseiam não apenas na execução última da violência, mas na construção de meios e de legitimação para isso, que são a rigor ideias que afirma o quando o outro é dignamente "menos".

Discriminação é o processo no qual membros de um grupo socialmente definido pertencem a esse grupo e são tratados de uma maneira particularmente e irracionalmente diferente no sentido de desvantagens sociais e morais. São comportamentos observáveis, atitudes caracterizadas por diferentes tratamentos desiguais de pessoas ou grupos devido à sua origem, pertences, aparência ou opinião, na escola, em casa, na rua. Manifesta-se no campo de ação como expressão de preconceito. O preconceito é uma ideia social e historicamente construída sobre um "tipo" de pessoa, feita de acordo com sua personalidade. Além do preconceito, o estigma se correlaciona com a discriminação. Isso ocorre porque os atributos de um indivíduo resultam em tratamentos injustos ou diferentes para indivíduos com atributos diferentes. O estigma é baseado no sujeito, no corpo e na experiência, e é descrito 
como uma marca, uma diferença no valor negativo relacionado à desigualdade social (BADALOTTI et. al., 2019).

No Brasil, poucos estudos analisaram as implicações de experiências discriminatórias por diferentes grupos e dados demográficos de uma perspectiva totalizante que não se limita a um tipo específico de discriminação, mas a uma associação entre a violência estudada e as características gerais da sociedade brasileira como um todo em termos de cultura, mito nacional e estrutura social. Além disso, pouco se sabe sobre estratégias eficazes para lidar com a discriminação em diferentes situações (BADALOTTI et. al., 2019).

A questão da violência tem sido discutida em várias áreas do conhecimento. Esse problema da aceitação da diversidade sexual é representado pelo preconceito, justificando a intolerância e ganhando cada vez mais espaço hoje com as ideologias "anti vitimistas" em moda no Brasil (HERZOG, 2019).

O processo para começar a mudança social no sentido de combate à violência no Brasil é a "quebra" do paradigma que reproduz o preconceito, começando com uma mudança na moralidade, como diz Bourdieu (2003), com uma grande modificação da estrutura social. Os sintomas da violência e as persistentes relações de poder, o padrão cultural da "heterossexualidade", não podem ser descartados, como tem sido quando a escola não combate a associação entre casamento e diferença entre sexos.

Segundo Saffioti (1999), a violência contra a mulher, principalmente a doméstica, tem gênero: o masculino. Isso independe do sexo físico do dominante. Mesmo naqueles casos em que há agressão por parte da mulher, esta estaria no exercício de sua função patriarcal, onde as ações se compreendem como sinais de um poder pequeno, ocorrendo devido a socialização onde a mulher é submetida.

Essa perspectiva do autor supracitado demonstra a violência doméstica na medida em que se encontra esta essência no masculino, mesmo que quem a pratica seja a mulher. Aqui se constrói dualidade entre vítima e algoz para explicação da violência. Essa dualidade tende a deixar brechas para o vitimismo que é prejudicial no âmbito 
das ciências humanas para compreender a violência, assim como na vida social porque mitiga possibilidades de transformação. Segundo Gregori (1993), a ideia de vitimismo está presente em várias pesquisas também feministas devido ao fato de se enfatizar ocorrências onde mulheres são vítimas diretamente, em contraste a outros casos em que mulheres praticam violência, onde se veem isso na perspectiva feminista enquanto ato de resistência ou como comportamento institucionalizado externamente. Essa dualidade "algoz e vítima" também é criticada por autores críticos e politicamente de esquerdas como Marilena Chauí (apud SANTOS e IZUMINO, 2005). Esta autora percebe a violência contra as mulheres enquanto expressão de dominação pelo homem, onde não há autonomia da mulher que é vista como cúmplice ou vítima da dominação masculina. Ocorre que, para a autora, essa cumplicidade não advém de livre arbítrio da mulher, pois sua subjetividade não tem autonomia. A mulher e sua subjetividade são instrumentalizadas no processo de dominação masculina.

A violência contra a mulher é onipresente no Brasil, ocorrendo em todas as classes, muito embora essa violência seja a regra e não a exceção em grupos sociais marginalizados, como aponta Jessé Souza (2009). Entretanto, a violência que ocorre no país não tem causa apenas individual, mas principalmente social: não são meras escolhas de homens, mas a reprodução de comportamentos que estão socialmente condicionados. As pesquisas sobre violência tendem a ocultar este fato ao não compreender o que significa dizer que a violência é social: há uma tendência para ver o "social" no sentido de relacionamentos, onde aquele que impetra a violência está dentro de uma sociedade e é por ela influenciada. Mas a violência é social em um sentido muito mais radical: ela é construída socialmente a partir do zero. A violência é toda ela social e isso quer dizer que a violência contra a mulher não tem apenas gênero, tem classe social. Superar a individualização da violência contra a mulher significa ir além do discurso sobre dominação masculina, incluindo a discussão sobre poder e classe social, pois, como afirma Jessé Souza (2009),

Para uma parcela significativa dos especialistas da "área da violência" inexiste, pasme o caro leitor, qualquer relação entre violência social e desigualdade social. O liberalismo-conservador dominante é, nesses casos, aplicado no sentido de evitar a percepção da "guerra de classes" subpolítica, na periferia das grandes cidades brasileiras, e interpretá-la, como sempre, como meros

RC: 103753

Disponível em: https://www.nucleodoconhecimento.com.br/lei/medidas-protetivas 
"desvios individuais". Toda a causalidade social desse conflito é obscurecida em favor de uma perspectiva superficial que o torna perceptível apenas como uma luta entre "indivíduos", cuja metáfora maior e mais evidente é o combate entre o policial e o delinquente.

Isso é importante para a discussão deste artigo porque a lei maria da penha prevê esforços institucionais para além da mera punição do agressor, esforços no sentido de prevenir a agressão contra mulheres. Ocorre que no Brasil, o cenário de violência contra a mulher, quando existe alguma política minimamente eficaz, é no sentido de punir o agressor, sem empreender políticas orientadas por uma compreensão do problema da desigualdade social: a violência contra a mulher não pertence a uma classe específica, mas enquanto em algumas classes sociais ela é a exceção, ocorrendo pontualmente, as vezes, na "ralé" brasileira ela é a regra, sendo a exceção a ausência de violência contra a mulher. Em estudos empíricos, Jessé Souza analisou dois tipos sociais comuns desta classe social: a empregada doméstica e a prostituta. Uma que leva uma vida dentro dos padrões que a sociedade pede, e outra que não leva a vida nesses padrões, estande quase na categoria, segundo o imaginário social, de delinquente que tem a prostituta no Brasil. Ambos os casos há história de violência, desde tenra idade, exercida por homens, primeiro pelo padrasto, depois por namorados e por fim pelo marido.

O que há em comum na história de vida das mulheres entrevistadas é um tipo de socialização familiar disruptivo, que irá impedir a transmissão afetiva de valores como disciplina, autocontrole e pensamento prospectivo, num contexto familiar marcado pela ausência da figura paterna e pela presença de relações instrumentais de todo tipo, a começar pela frequência e naturalização de abusos sexuais sofridos na infância por essas mulheres. Além da carência, em qualquer medida significativa, de conhecimento resultante de um capital escolar incorporado, essas mulheres em sua infância nunca foram percebidas como "um fim em si mesmas", como crianças com desejos, sentimentos, aspirações, medos e angústias que necessitavam de cuidado, proteção e afeto. (SOUZA, 2009, p. 176)

Nesta passagem, o autor propõe que no Brasil, há toda uma classe social cuja violência contra a mulher é o "pão cotidiano", principalmente na forma de agressão física e abuso sexual e assédio. Para além dessa violência, existe a violência psicológica cotidiana, onde o autor conta o caso, segundo ele também muito comum, de adolescentes que se sentem assediadas por padrastos, como no caso real a seguir

RC: 103753

Disponível em: https://www.nucleodoconhecimento.com.br/lei/medidas-protetivas 
narrado por Souza (2009) acerca de uma adolescente cujo padrasto verificava com regularidade os absorventes.

Eu engravidei e escondi a barriga porque meu padrasto pegava e conferia se eu tava usando modess. Então, eu pegava o modess, entrava no banheiro, furava meu dedo e passava o sangue no modess pra fingir que eu tava menstruando porque meu padrasto conferia o modess e tudo. (SOUZA, 2009, p. 190)

No caso da violência que está apreciada na legislação, com a denúncia da agressão, o acusado passa por um processo de julgamento. Enquanto isso ocorre, ele pode ficar em liberdade, o que apresenta perigo de nova agressão, coação e pressão psicológica e emocional sobre a vítima. Em face desse contexto e de outros problemas, a Lei Maria da Penha coloca à disposição do poder judiciário um leque de medidas protetivas de urgência para proteção da mulher. São diversas medidas disponíveis onde o juiz escolhe as mais cabíveis dependendo de cada caso.

Segundo dados recentes, as agressões era sobre de $42 \%$ das mulheres no país em 2019 passando para 48,8\% em 2020 em contexto de pandemia. Aqui, houve diminuição de agressões contra mulheres nas ruas, mãos aumento da agressão em casa, de 29\% para 19\% (PAULO, 2021; PAULO e ACAYABA, 2019). Ou seja, quase metade das mulheres sofreram algum tipo de agressão física no país nos últimos anos. Se somarmos a essas agressões mais visíveis com aquele tipo de agressão simbólica, não denunciável pela sua invisibilidade, pode-se afirmar que no Brasil, a violência contra a mulher é uma regra e não a exceção.

A Lei no 11.340 de 2006 (BRASIL, 2006) é denominada "Maria Da Penha" devido às agressões físicas e psicológicas que Maria Da Penha Maia Fernandez sofreu em sua família por seu marido, professor universitário. Criou uma resposta internacional. Como resultado, Maria da Penha só encontrou mais poder para elevar sua luta pelos direitos humanos das mulheres a níveis internacionais, apesar da ineficácia do sistema jurídico brasileiro. O país tinha imagem negativa nesse aspecto perante as convenções de direitos humanos e precisara tomar providências e proteger as mulheres das agressões. 
No entanto, essas medidas falharam em reduzir a desigualdade entre homens e mulheres. $O$ índice de ataques a mulheres foi muito alto quando a lei foi aplicada, especialmente considerando a violência doméstica. Estudos realizados por organizações não-governamentais e pesquisas de opinião indicam uma alta incidência de violência doméstica no país, com muitas mulheres denunciando, apesar das medidas de punição e proteção serem eficazes.

A lei é contrária à cultura muito medíocre de tratamento dado por homens a mulheres no Brasil, desde o início até o presente, que era considerado um comportamento comum por muitas gerações. A lei exige uma definição de violência contra as mulheres que pode se manifestar de várias maneiras, incluindo física, moral, psicológica, patrimonial, sexual.

Art. 1ํㅗㄴ Esta Lei cria mecanismos para coibir e prevenir a violência doméstica e familiar contra a mulher, nos termos do $\S 80$ do art. 226 da Constituição Federal, da Convenção sobre a Eliminação de Todas as Formas de Violência contra a Mulher, da Convenção Interamericana para Prevenir, Punir e Erradicar a Violência contra a Mulher e de outros tratados internacionais ratificados pela República Federativa do Brasil; dispõe sobre a criação dos Juizados de Violência Doméstica e Familiar contra a Mulher; e estabelece medidas de assistência e proteção às mulheres em situação de violência doméstica e familiar (BRASIL, 2006).

Segundo Thiago Ávila, quando a lei foi promulgada e aplicada, ela estava sob intenso debate, onde a sociedade procurava mecanismos para conter a violência contra as mulheres. Portanto, a nova legislação afirma claramente que é responsabilidade do estado alterar a desigualdade de gênero, a fim de garantir o direito das mulheres à vida livre de violência com suas famílias e sociedades (artigo $3^{a}$ ). A lei inclui uma declaração dos direitos da mulher, prescrita de maneira geral na constituição, mas a descrição em certos diplomas legais sobre a mulher é uma importante forma de comunicação social. Para as mulheres sugerem uma mudança de paradigma em relação à não aceitação da violência (ÁVILA, 2007).

As mudanças propostas, que são implementadas como uma maneira de acabar com a prática de homens violentarem mulheres no âmbito familiar e doméstico, não são apenas culturais, mas também legais. Se essa violência era grande, era sempre

RC: 103753

Disponível em: https://www.nucleodoconhecimento.com.br/lei/medidas-protetivas 
contra alguém que vivia pela família ao lado do parceiro e muitas vezes abandonava suas vidas para cuidar de seus maridos, casas e filhos. Segundo Marcelo Lessa Bastos, o número de mulheres espancadas pelo marido é impressionante, além de sofrer todos os tipos de violência, desde humilhação a ataques físicos. A violência sexual é provavelmente a forma mais preocupante de violência. Literalmente, nesses casos, as vítimas precisam dormir com o inimigo por causa da absoluta falta de alternativas (FREITAS, 2007).

Diante dessa violência, há uma profunda penetração no mundo de dor e sofrimento, onde mulheres e crianças vivem submissas. Stella Cavalcanti aponta em sua opinião sobre o assunto que no Brasil a violência contra as mulheres não atende a restrições de idade, status social, etnia ou religião. Seus sintomas variam e muitos encontram fortes raízes culturais. Entre eles, destacam-se os ataques físicos, sexuais e emocionais (CAVALCANTI, 2018).

O artigo 7 da Lei oㅜ11. 340/06 tipifica a violência doméstica, explicando com clareza o que é cada mecanismo utilizado para gerar violência contra a mulher, apresentado com o mesmo significado que a violência familiar, neste caso violência, física, moral, psicológico, sexual e patrimonial. A violência sempre foi usada pelos homens para colocar as mulheres em posições mais baixas, indicando sua posição legítima na sociedade. Porque ele tem que controlar a mulher e a família. Afinal, ele é um "homem da casa". Ela deve se limitar ao trabalho doméstico (TELES e MELO, 2002).

Esses ataques sofridos pelas mulheres não apenas produzem dor físico, mas também se estendem a mente que fica completamente abalada; o desamparo causa solidão, aceitação, ressentimento, vergonha e exacerba a situação. As mulheres não podem ver esse relacionamento como submissão. A existência de violência e discriminação contra as mulheres não é nova. No Brasil, até 1830 , os homens podiam legitimamente matar mulheres infiéis. Mas o mesmo não acontecia quando os homens traíram as mulheres (TELES e MELO, 2002).

Exemplo de violência não física é o caso delimitado por Rogerio Sanchez Cunha que descreve violência psicológica: um ataque emocional (físico ou mais grave). O 
comportamento típico ocorre quando um agente ameaça, rejeita, humilha ou discrimina uma vítima, mostra alegria quando os outros sentem medo, inferioridade, fraqueza e constituem uma obsessão (CUNHA; PINTO, 2008).

Quando uma mulher é espancada, sua dignidade é violada. A Constituição Federal baseia-se na dignidade humana (Artigo 1, III), e esse princípio básico não pode ser violado por qualquer pessoa, nem mesmo renunciado por conta da própria vítima (CAVALCANTI, 2018).

Existem vários tipos de violência contra as mulheres, a exemplo de estupro, assédio sexual, ferimentos, intimidação, assassinato e até mesmo o sofrimento psicológico da vítima. O assédio sexual está na lei penal brasileira ํo 10.224, de 15 de maio de 2001. $\mathrm{O}$ art. 216-A estabelece punição pela detenção de uma pessoa que tem humilha de alguém por ganho ou favor pessoal, utilizando o status hierárquico superior como cargo por exemplo (BRASIL, 1940).

O assédio sexual, geralmente, está atrelado a cantadas que ocorrem no local de trabalho, mas pode envolver intimidação, além de ter um caráter agressivo. A perseguição permanente ao crime causa agitação física e moral na vítima, por exemplo, sucumbindo à intimidação por medo de perder o trabalho (TELES e MELO, 2002).

Quando se trata de violência doméstica contra as mulheres, lesões corporais são um dos crimes mais comuns. No direito penal brasileiro é típico do artigo 129 o dano ao corpo, que prejudica a integridade ou a saúde, dando prisão por três meses a um ano. As lesões que as tornam incapacitadas em ocupações habituais por mais de 30 (30) dias são consideradas de natureza séria. Isso compromete a vida, fraqueza permanente dos membros, sensação ou função e trabalho. No caso de aborto, as penas são de dois a oito anos de prisão. Se a morte ocorrer, a pena de lesão corporal é de 4 a 12 anos de prisão (BRASIL, 1940).

O artigo $129-\S^{\circ}$ afirma que resulta da violência doméstica quando cometida contra um ascendente, descendência, irmão, cônjuge ou companheiro que mora junto ou 
está hospedada. Antes da Lei 11.340 / 2006, as penas especificadas neste parágrafo eram de seis meses a um ano de prisão. Com o advento da lei, a sentença foi aumentada de três meses para três anos, continuando sentença de detenção (BRASIL, 1940).

\subsection{FUNDAMENTOS CONSTITUCIONAIS DA LEI MARIA DA PENHA}

Quando a lei foi anunciada, foi criticada e alguns erros foram apontados, questionando seu caráter inconstitucional, impedindo sua eficácia e tentando limitar sua efetividade. Mencionando a diferença entre o tratamento de homens e mulheres e os fundamentos do problema, a sociedade machista está tentando justificar de maneira medíocre a constitucionalidade das medidas de proteção sob a lei.

O principal ponto discutido aqui é justamente a constitucionalidade da Lei 11.340 / 06, que trata as mulheres como frágeis e alguns líderes políticos que dizem que deixar os homens vulneráveis é discriminatório. Nesse sentido, refere-se ao entendimento de João Paulo de Aguiar Sampai e Tiago Abu Dada Fonseca. Estes autores afirmam que não é necessário muito esforço para perceber que a legislação de trata a situação de homens e mulheres e a situação de crianças de maneira diferente. $O$ poder constitucional o tratou igualmente, mas a Lei Maria da Penha está causando desigualdade na entidade familiar (SOUZA; FONSECA, 2006).

Nesta discussão, Alexandre Magnokoleia afirma que, de repente, pequenos atritos diários podem ser considerados um crime ou causar supostos danos morais. Sob a desculpa de proteger as mulheres, a lei a considera incapaz de cuidar da saúde mental e pode "prejudicar sua autoestima" pelas palavras e dissonância dos parceiros (CORREIA, 2016).

A constitucionalidade da lei mencionada foi criticada por ser um texto feminista que demonstra proteção excessiva para as mulheres e prova ainda que as mulheres são sempre tratadas como "sexo fraco". A primeira crítica à lei diz respeito à avaliação do artigo 5 da Constituição de 1988, que afirma no preâmbulo que todos são iguais perante a lei, sem distinção de qualquer natureza, garantimos que brasileiros e 
estrangeiros têm direitos invioláveis: direitos à vida, liberdade, igualdade, segurança e propriedade, e sua subseção I afirma que homens e mulheres são iguais em direitos e obrigações.

Se a comparação for feita no campo criminal, o tratamento é igual e homens e mulheres são responsáveis por crimes de assassinato ou lesões corporais na medida do possível e não há diferença nas penalidades. Algumas disposições da Lei 11.340 / 06 apontam que é inconstitucional porque violam princípios de igualdade, proporção etc., pois distinguem homens e mulheres com presunção de culpa.

A esse respeito, a juíza do Rio Grande do Sul Maria Berenice Diaz defende que o tratamento favorável das mulheres é justificado pelos critérios de avaliação, por exemplo, para dar um equilíbrio social existencial. A lei Maria da Penha é, portanto, constitucionalmente compatível (DIAS, 2007) porque serve como um elemento de igualdade de fato e de conformidade com as condições da Magna Carta.

A lei trouxe algo novo. Medidas de proteção para as mulheres que mais sofrem violência doméstica em casa. Nesse caso, o princípio da igualdade é formal e legal, portanto, não há dano ao princípio da igualdade. Nesse contexto, buscamos igualdade de equilíbrio entre as partes, para que os homens não prejudiquem as mulheres. Considerando o alto índice de discriminação, as mulheres são as mais afetadas pela violência. Portanto, alcance uma igualdade significativa com as disposições legais. Há críticas à igualdade entre homens e mulheres, crianças e enteados. Eles frequentemente sofrem com esse tipo de violência, são discriminados por seus pais, padrastos, etc. e são humilhados e estuprados.

Quanto ao homem, ela deve ser tratada de maneira completamente diferente. Não existe discriminação e injusta a favor das mulheres. Pelo contrário, o que procuramos equilibrar são as medidas cautelares oferecidas por lei. No contexto cultural em que vivemos, as mulheres ainda não estão prontas para responder à força dos homens. Alcançar o potencial físico dos homens exige proteção, pois ela é a pessoa que mais sofre.

RC: 103753

Disponível em: https://www.nucleodoconhecimento.com.br/lei/medidas-protetivas 
Nesses casos, os ataques às crianças são julgados pelo JECrim e os ataques à filha são julgados como violência doméstica. Portanto, eles se encaixam como Maria da Penha. Isso não é mais feito com a Lei oㅜ 9.099 / 1995. Se a violência familiar é cometida contra um homem ou mulher no caso de um ataque por parte dos pais, ela é discriminada. Está sob a jurisdição do Tribunal de Violência contra as Mulheres. Mas não resolve os seguintes problemas: bater na filha menor, Maria da Penha, já bater no filho menor, algo distinto. No entanto, lembre-se de que os ataques esporádicos precisam ser diferenciados dos que se repetem em um ciclo de violência.

A maioria das mulheres desiste de culpar maridos, parceiros, irmãos, pais, etc., por medo ou culpa. O maior problema nesses casos é o próprio preconceito, que já é socialmente relevante, com muitos traços de patriarcado remanescentes e tratando a violência masculina contra as mulheres como normal. Um homem foi classificado como um forte sexo, ganhador desde o início, ele acredita que tem maiores poderes de comando porque é quem "mais trabalha". Essa visão é um dos grandes fundamentos da violência doméstica, embora desatualizada. A maneira como os homens são criados é manter essa fundação firme com provérbios populares. Dizem às crianças que os homens não choram e que a sensibilidade é para as mulheres.

O preconceito proibiu meninas de brincar com meninos na infância e detido pelos pais em uma visão crítica e sensível ao gênero de que as mulheres precisam aprender a cozinhar para cuidar de sua casa e do marido. No entanto, essa situação mudou com o surgimento da modernização e das mulheres independentes, mas o mundo ainda é algo que geralmente pode ser classificado como hetero e ainda não foi preparado para a grande evolução das mulheres. Porque vem da própria mulher. Especialmente quando você sabe que é normal e tenta repassá-lo para sua filha ou neta, como no caso de uma avó que cresceu com esse sistema, esses eventos têm sérios problemas. O sistema precisa abordar sua prevenção e repressão.

Agressão é a forma que os homens usam para reafirmar seu poder. Em outras palavras, é apenas uma forma de controle. Esse controle prende a mulher a rebaixála, a ataca verbal e fisicamente, tenta colocá-la mais baixa e a faz acreditar de alguma maneira que ele é melhor. Como pode ser visto nas maneiras de orientar, muitas

RC: 103753

Disponível em: https://www.nucleodoconhecimento.com.br/lei/medidas-protetivas 
vezes vale a pena mencionar que a violência psicológica causa mais trauma e dano do que a própria violência física. A depressão é mais comum entre mulheres abusadas que nem sabem que estão sofrendo esse distúrbio. Tem medo de como será visto pela sociedade. O pior momento é quando as mulheres não conseguem superar esse problema.

Em relação ao conflito com os regulamentos do art. 98, I, da Constituição Federal, que prevê a criação de um tribunal criminal especial, de acordo com a Lei oํ 11 340/06. Verifica-se que era um princípio de isonomia e o fato de a lei Maria da Penha não se aplicar a outros delitos. Não há aplicação do art. 88 da lei 9.099 / 95 para justificar a inconstitucionalidade. No entanto, neste último caso, o princípio da igualdade pode justificar a natureza inconstitucional e constitucional da Lei 11340/06, uma vez que a nova expressão jurídica é um tipo de ação positiva, como no caso da cota de negros.

A lei Maria da Penha foi enfatizada na forma de sua punição, que é uma ação criminal condicional, mas é reivindicada como incondicional em relação a ferimentos graves, tornando o assunto muito controverso. Está se formando. A tradição brasileira afirma que cabe às mulheres cuidar de seus filhos e seus lares, mas essa visão está mudando cada vez mais para as mulheres, buscando igualdade, assim, dando aos homens uma sensação de perda de controle. Usando ataques para recuperar o "poder" na prevenção de tal violência em situações que evocam e os guiam. Nesse contexto, a Lei oํ 11.340 / 06 substitui a Lei no 9.099 / 95.

Mesmo denunciando, muitas mulheres procuram retirar a denúncia de ameaças ou repressão da própria família, mas hoje não há como retirá-la. As vítimas de violência doméstica podem pedir à audiência que nenhuma queixa seja feita contra o agressor e manter a integridade física. Portanto, se pode solicitar a retirada, em juízo, da representação feita contra o agressor. Mas 0 Tribunal decidirá se aceita ou não o pedido de retratação. Esse entendimento vem do TJDF. Segundo os juízes, a possibilidade está prevista no artigo 16 da Lei Maria da Penha. No entanto, o juiz e o promotor devem ter cuidado para descobrir se a atitude da vítima é espontânea ou não. Todas as decisões dependerão da análise de cada caso. 
Se uma queixa for apresentada, será de interesse público e o processo será do interesse do Ministério Público representado por seu procurador para investigar se a vítima realmente deseja retirar ou se se sente ameaçada, pressionada a retirar. Antes disso, ela deve passar por uma audiência preliminar com o juiz e dizer por que o caso foi arquivado.

\subsection{INEFICÁCIA DAS MEDIDAS PROTETIVAS}

As medidas protetivas de emergência que obrigam os agressores estão descritas no artigo 22 da Lei 11.340. De acordo com as disposições desta Lei, depois de confirmar as práticas de violência contra as mulheres, os juízes podem aplicar imediatamente, entre outras coisas, as seguintes medidas contra os agressores em conjunto ou separadamente: restrições ao porte de armas com contato com a autoridade competente; remoção de casa, local de residência ou contato com a vítima. Também pode haver a proibição de certos atos: abordar a vítima, sua família e testemunhas, devendo estabelecer a distância mínima entre os agressores e testemunhas, assim como suas famílias. Parar de entrar em contato com determinados lugares em prol de não ofender a vítima. Suspensão de visitas ou restrição a dependentes menores após consulta com equipe multidisciplinar ou serviços semelhantes. Prestação de alimentação. Os juízes podem solicitar a assistência da polícia em qualquer instante buscando assegurar a eficácia das medidas estipuladas no artigo 22 da Lei supracitada.

Muitos casos não são relatados por medo em relação ao agressor. A mulher agredida esconde a triste realidade, pois vive com medo diante das ameaças do companheiro. A Lei Maria da Penha foi introduzida porque estava tentando acabar com essa situação que as mulheres viviam, instando-as a buscar ajuda e acabar com a realidade violenta que vivenciam em casa. É importante notar que toda violência contra a mulher é prejudicial à sua integridade física e saúde, e não somente lesão corporal. Para se constituir em lesão corporal, a vítima deve apresentar algum dano ao corpo, que pode ser prejudicial à saúde e até causar choque psicológico (NUCCl, 2009).

RC: 103753

Disponível em: https://www.nucleodoconhecimento.com.br/lei/medidas-protetivas 
Mesmo que tenha proteção para as vítimas, a situação não pode ficar apenas sobre a alçada da Justiça Penal, porque o Estado precisa institucionalizar programas para tratar os agressores. O CP lista diversas penas restritivas de direito para o agressor. Limite de fim de semana disposto no artigo 43, VI é uma delas, que faz com que o agressor se mantenha em sábado e domingo por 5 horas por dia, na casa de albergado. Nesse momento deve participar de palestras como atividade educativa, conforme explica Dias (2007) ao citar o artigo 48, parágrafo único da CP e o artigo 15 da LEP.

Após a aplicação da pena supracitada, a lei Maria da Penha autoriza o juiz a ordenar que o réu participe de programas de reabilitação e reeducação. $O$ juiz poderá ainda decidir aplicar outras medidas ao agressor, além de servir às comunidades e órgãos públicos, proibindo temporariamente o uso de direitos e congelando bens (DIAS, 2007).

Essas medidas são tomadas para reconhecer que o agressor é incapaz de realizar tal ato porque não é o proprietário da mulher (DIAS, 2007). Sabe-se que o estado é falho nesse sentido, já que a pena é descrita no direito penal, mas não há especialistas suficientes na esfera psicossocial. Cabe, então, ao Estado agir diretamente com os agressores e vítimas, e garantir a atenção das vítimas e a capacitação permanente de especialistas para lidar com os agressores (TELES e MELO, 2002).

A Lei 11.340 cria um mecanismo para impedir a violência contra mulheres e estabelece alguns apoios e salvaguardas para as mesmas. Os verbos associados a essa lei ajuda a prevenir, punir e erradicar todas as formas de violência contra a mulher que podem ser prevenidas, punidas e eliminadas. Por esse motivo, foram esclarecidas ações entre esferas federais, estaduais, prefeituras e organizações não governamentais com o objetivo de adotar programas de prevenção para coibir a violência contra a mulher (CUNHA e PINTO, 2008).

A lei estipula que as ações legais apropriadas devem ser tomadas assim que as autoridades policiais tomem conhecimento das práticas de violência. Também precisa garantir a proteção policial das mulheres. Enviar para um hospital, clínica ou 
laboratório forense. Se houver risco de vida configurado, fornece um abrigo seguro. Levar a mulher ao local de origem para garantir a retirada de seus pertences e comunicar os direitos garantidos por esta lei e os serviços disponíveis. Tais medidas apoiam as mulheres que buscam segurança com o auxílio das autoridades (CUNHA e PINTO, 2008).

Desse modo, os traços simbólicos de dispositivos presentes na Lei 11.340 tem certo grau substancial de eficiência prática, e estimulam aprendizados sociais e formação de novas ideias que orientam medidas efetivas para solucionar a discriminação contra o sexo feminino (SOUZA, 2008).

As medidas de proteção visam suprimir os agressores e proteger as vítimas. Isso não era realista no dia a dia, já que as mulheres estão à mercê de seus parceiros violentos. A Lei 11.340 foi criada para proteger as mulheres dos homens. Mas se em certo aspecto é aplicada de forma eficaz, em outra dimensão, por falta de preparo das instituições do Estado, a autoridade competente não o pode fazer cumprir todos os pressupostos da Lei Maria da Penha. Ou seja, as medidas protetivas são eficazes em sua forma lógica, o grande problema está em sua implementação da prática pelos órgãos públicos. A ineficácia das medidas protetivas não está em sua estrutura ou no que propõe, o que de fato o faz de forma plena: as medidas, se executadas com eficiência pelos órgãos públicos, protegem de fato a mulher do seu agressor. $O$ problema está exatamente na implementação das medidas protetivas.

A ineficácia das medidas protetivas está na conexão entre os diversos órgãos que atuam para realização das medidas. A Lei dá uma série de diretrizes para proteção da mulher, e o poder judiciário estabelece as devidas medidas a serem cumpridas. Ocorre que o cumprimento não depende apenas do juiz, mas do sistema policial, ancorado em valores machistas, dos outros órgãos públicos.

Entretanto, para efetivação da lei é necessário que o resultado proposto seja atingido em todos os seus artigos. Se verifica no cenário atual ainda que os dados sobre violência contra a mulher não sugerem motivos para comemoração, já que a diminuição das agressões ocorre ainda de maneira insuficiente (LACERDA et al, 
2018), havendo não apenas muita violência no país contra a mulher, quanto inúmeros casos de reincidência.

Bruno (2010) afirma que existe grande negligência da aplicação da lei por órgãos do Estado, tanto judiciário quanto o executivo, o que facilita impunidade acerca da agressão, por falta exatamente da eficácia da lei Maria da Penha. Isso parece ocorrer devido ao fato de as instituições responsáveis pela execução da lei agir inadequadamente por razões culturais e institucionais. Essas instituições têm obrigação de criar formas de facilitação para fiscalizar, aplicar a proteção da vítima. Como afirma Carneiro (2010), a lei garante o direito, mas cabe as instituições responsáveis aplicar a lei. Tem que dar as mulheres condições favoráveis para lidar com a situação de agressão e possibilidade de impedir sua reincidência.

Ao assinar a Lei Maria da Penha, o presidente deveria ter construído junto com ela órgãos oficiais para sua aplicabilidade e fiscalização integral, assim como instituições de apoio as mulheres vítimas. A mera Lei Maria da Penha não basta. Sem instituições especializadas em sua fiscalização e suporte ela não surte eficácia plena (MATTJE, 2015). Bruno (2010) afirma que mesmo que a lei exista para proteger a vítima através de proteção e de assistência, verbos como "erradicar", "coibir", "punir", "prevenir", traz a ideia pressuposta de que se pode punir a violência doméstica, mas na prática as mulheres continuam sendo violentadas de forma alarmante de várias formas, com casos sem denúncia em virtude de ameaças ou outra razão.

O governo tem falhado nessa eficácia desejada por negligência já que as punições estão no código penal em lei 2.848 de 1940 para ser usada pelos juízes. Ocorre que as providências que devem ser praticadas para prevenir a violência aliada a ausência de fiscalização da delegacia e juizados não estão sendo cumpridas conforme a lei Maria da Penha. Falta as instituições do Estado agir de maneira mais responsável com políticas públicas assertivas (LACERDA et al, 2018).

As medidas protetivas têm ineficácia é um fato empírico facilmente notado ao se notar os dados quantitativos sobre agressão e o grau de reincidência. A falta de fiscalização e de políticas públicas especializadas é uma das causas dessa ineficácia. A lei existe 
e constitui avanço grande, mas o problema está em sua aplicabilidade. A reincidência tem sido, inclusive, tema de grandes debates sobre violência doméstica, havendo nos crimes gerais cerca de $70 \%$ de reincidência (SAPORI et al., 2017), sendo que para a violência doméstica os dados são similares segundo Silva (2015). Isso sugere que a violência doméstica é um crime muito complexo e não pode ser mitigado apenas com a operacionalização da justiça penal. São necessárias políticas para unir forças no combate a essa ineficácia das medidas protetivas.

No caso da lei 13.827 de 2019 que modifica a Lei Maria da Penha, seu objetivo fundamental foi facilitar a aplicação das medidas protetivas. Buscou facilitar a tomada de decisão da justiça e da delegacia dando maior poder a essas duas instâncias para adotar medidas emergenciais para proteção da mulher. Assim, ao se notar o risco para a mulher ou seus filhos, o agressor deve de forma urgente ser afastado do lar. Os presos não têm liberdade concedida até que se constate ausência de risco para a vítima. Isso para imprimir rigor maior a proteção, conforme o artigo 12, C, § 2 .

Mas mesmo com essas mudanças, não se pode falar que as medidas protetivas se tornaram eficazes, muito embora tenha havido avanços. Mesmo após os avanços na legislação brasileira nas últimas décadas, as mulheres são espancadas de forma quase que naturalizada na sociedade (LANGLEY e LEVY, 1980).

Ocorre que, reiterando, é na atuação das delegacias, juízes e promotores que se encontra as dificuldades para eficácia plena das medidas. É preciso compreender que o que causa a violência doméstica está associado a preconceitos, discriminação onde dominação de gênero ocorre. Os elementos culturais e institucionais (nos termos de FOUCAULT, 1993) que criam a violência doméstica estão também presentes nas pessoas que compõem as instituições encarregadas de operacionalizar as medidas protetivas de urgência. É preciso antes de tudo superar a visão de uma Justiça separada da sociedade, como se a lei e os operadores da lei fossem seres associais, que vivem fora da sociedade, tematizando e agindo sobre ela. Policiais, juízes, promotores, funcionários públicos são homens e mulheres e não há razão alguma para fundamentar que os mesmos valores, preconceitos, discriminação, relações de poder entre gêneros não estão presentes aí também.

$\mathrm{RC}: 103753$

Disponível em: https://www.nucleodoconhecimento.com.br/lei/medidas-protetivas 


\section{CONCLUSÃO}

A Lei Maria da Penha é um grande avanço na proteção das mulheres em relação a violência exercida contra elas pelos homens. A base dessa violência se encontra em uma cultura machista que, historicamente, não montou um conjunto de instituições aparelhadas para proteção antecipada da mulher: escolas que discutam constantemente a violência contra a mulher, políticas culturais direcionados a possibilitar aprendizados sociais ligados à cidadania, à igualdade de gênero.

A Lei Maria da Penha veio para fazer diferença frente a uma trajetória de avanços que ocorria de forma muito lenta no Brasil. Até sua promulgação, as mulheres não dispunham de aparato legislativo próprio para sua proteção, o que é necessário dado o contexto de poder e vulnerabilidade nas relações entre gêneros. Nesse contexto, a lei foi um grande marco nos direitos das mulheres no Brasil. Seus dispositivos parecem ter sido montados com seriedade e preocupação autêntica em realizar uma mudança.

As medidas protetivas foram, dentro dessa lei, um avanço a parte, já que enquanto o agressor é julgado e não apenas depois, é necessário a proteção da mulher por interferência do poder judiciário que precisa fazer uso das medidas protetivas para impedir ação do agressor sobre a mulher, seja pela coação ou por nova agressão.

A questão norteadora deste artigo incidiu sobre em que sentido as medidas protetivas de urgência são ineficazes. Pode-se concluir que o sentido é o seguinte: a lei tem uma intenção clara de proteger a mulher e prevenir a reincidência da violência doméstica. A lei tem dispositivos que, se aplicados, conseguem trazer mudanças grandes no cenário de violência, contribuindo para sua diminuição radical. Entretanto, é na aplicabilidade das medidas protetivas, em sua prática, que está a ineficácia. A proposta aqui é a seguinte: isso ocorre porque o posicionamento do Estado não percebeu que os elementos culturais e institucionais que estão nas famílias e que causam a violência doméstica, estão presentes também, em alguma medida, em delegacias e outros órgãos. Como foi apontado neste artigo, a violência contra a mulher está estruturada por mecanismos de dominação masculina e por mecanismos

RC: 103753

Disponível em: https://www.nucleodoconhecimento.com.br/lei/medidas-protetivas 
de classe social em seu grau de incidência em alguns contextos sociais. O Estado precisa construir políticas em observância ao fato de que na polícia também pode haver machismo, assim como na delegacia, ministério público e no poder judiciário. É possível propor a tese de que as medidas protetivas são ineficazes porque se pressupõe que aqueles órgãos responsáveis pela sua operacionalização são providos de preconceitos, de elementos culturais submetidos a dominação masculina.

\section{REFERÊNCIAS}

ÁVILA, Thiago André Pierobom de. Lei Maria da Penha: uma análise dos novos instrumentos de proteção às mulheres. Jus Navigandi, Teresina, ano 12, n. 1611, 29 nov. 2007. Disponível em: <http://jus2.uol.com.br/doutrina/texto.asp?id=10692>. Acesso em: 28 Abr. 2021.

BADALOTTI, T. S. et al. O enfrentamento ao fenômeno discriminatório em uma população de adultos. Physis: Revista de Saúde Coletiva, 29(4), e290415. Epub November 25, 2019. Disponível em: <https://doi.org/10.1590/s010373312019290415>. Acesso em: 28 Abr. 2021.

BOURDIEU, P. Sobre o poder simbólico. Rio de Janeiro: Bertrand Brasil, 2003. Pág. 118

BRASIL. Código Penal. Decreto Lei 2.848 de 7 de dezembro de 1940. Disponível em: <http://www.planalto.gov.br/ccivil_03/decreto-lei/del2848compilado.htm>. Acesso em: 28 Abr. 2021.

BRASIL. Decreto Lei $\mathbf{N}^{\circ} \mathbf{. 1 3 . 8 2 7}$, de 13 de Maio de 2019. Disponível em: < http://www.planalto.gov.br/ccivil_03/_ato2019-2022/2019/lei/L13827.htm>. Acesso em: 28 Abr. 2021.

BRASIL. Decreto-Lei №. 2.848, de 7 de Dezembro de 1940 - Código Penal. Disponível em: < http://www.planalto.gov.br/ccivil_03/decreto-lei/del2848.htm>. Acesso em:28 Abr. 2021. 
BRASIL. Lei № 11.340, 7 de agosto de 2006. Diário Oficial da República Federativa do Brasil. Brasília: 8.08.2006. Disponível em: <http://www.planalto.gov.br/ccivil_03/_ato2004-2006/2006/lei/111340.htm>. Acesso em: 28 Abr. 2021.

BRUNO, Tamires Negrelli. Lei Maria da Penha $\mathbf{x}$ Ineficácia das Medidas Protetivas. 2010. Disponível em: <https://monografias.brasilescola.uol.com.br/direito/lei-mariapenha-x-ineficacia-das-medidas-protetivas.htm> . Acesso em: 28 Abr. 2021.

CARNEIRO, Fabiana D. O Estado na Garantia do Cumprimento da Medida Protetiva de Proibição do Agressor de se Aproximar da Ofendida da Lei 11.340 de 7 de agosto de 2006. Monografia. Faculdade do Norte Novo de Apucarana FACNOPAR. 2010. Disponível em: <https://facnopar.com.br/conteudoarquivos/arquivo-2017-06-14-14974685662075.pdf> Acesso em 28 Abr. 2021.

CAVALCANTI, Stela Valéria Soares de Farias. A violência doméstica como violação dos direitos humanos. 2018. Disponível em: <www.jus2.uol.com.br/doutrina/texto.asp?is=7753>. Acesso em: 28 Abr. 2021.

CORREIA, Alexandre Magno. A constitucionalidade da Lei $\mathbf{n}^{\circ}$ 11.340/06. 2016. Disponível em: <www.direitonet.com.br/artigos/x33>. Acesso em: 28 Abr. 2021.

CUNHA, Rogério Sanches; PINTO, Ronaldo Batista. Violência Doméstica-Lei Maria da Penha (Lei 11.340/2006) Comentada artigo por artigo. São Paulo: Editora Revista dos Tribunais, 2008. Pág. 132.

DIAS, Maria Berenice. A lei Maria a Penha na Justiça: a efetividade da Lei 11.340/2006 de combate à violência doméstica e familiar contra a Mulher. São Paulo: Editora Revista dos Tribunais, 2007. Pág. 36.

FOUCAULT, M. História da Sexualidade I: A Vontade de Saber. Rio de Janeiro: Graal, 1993. Pág. 138. 
FREITAS, André Guilherme Tavares de. Estudos sobre as novas Leis de Violência Doméstica contra a Mulher e de Tóxicos (Lei 11.340/2006 e 11.343/2006). Rio de Janeiro. Editora Lumem Júris, 2007. Pág. 47.

HERZOG, Regina. Do Preconceito À Intolerância: Quando Se Rouba A Humanidade Do Outro. Ágora: Estudos em Teoria Psicanalítica, 22(3), Epub September 23, 2019. Disponível em: <https://doi.org/10.1590/180944142019003002>. Acesso em: 28 Abr. 2021.

LACERDA, Antonio Wilson et al. A Ineficácia da Aplicação das Medidas Protetivas frente á Lei Maria da Penha (Lei n.11.340/06). 2018. Pág. 17.

LANGLEY, Roger; LEVY, Richard C. Mulheres espancadas: fenômeno invisível. 2.ed. São Paulo: HUCITEC, 1980. Pág. 193.

MATTJE, Gustavo André. Descumprimento de Medidas Protetivas de Urgência no Âmbito Domestico e Familiar contra a Mulher: Aspectos e Consequências. Centro Universitário UNIVATES. Lajeado, jun 2015. Pág. 129.

NUCCI, Guilherme de Souza. Manual de direito penal: parte geral: parte especial. 5.ed. São Paulo: Editora Revista dos Tribunais, 2009. Pág. 327.

PAULO, Paula Paiva. G1 - Uma em cada quatro mulheres foi vítima de algum tipo de violência na pandemia no Brasil, aponta pesquisa. 2021. Disponível em: https://g1.globo.com/sp/sao-paulo/noticia/2021/06/07/1-em-cada-4-mulheres-foivitima-de-algum-tipo-de-violencia-na-pandemia-no-brasil-diz-datafolha.ghtml. Acesso em: 10 Ago. 2021.

PAULO, Paula Paiva; ACAYABA, Cíntia. G1 - Violência contra mulheres praticada por vizinhos cresce; uma em cada cinco relata agressão, diz Datafolha. 2019. Disponível em: https://g1.globo.com/sp/sao-paulo/noticia/2019/02/26/violenciacontra-mulheres-praticada-por-vizinhos-cresce-uma-em-cada-cinco-relata-agressaodiz-datafolha.ghtml Acesso em: 10 Ago. 2021. 
SANTOS, C. J. Crimes de preconceito e de discriminação. Editora Saraiva: São Paulo, 2017. Pág. 72.

SAPORI, Luis Flávio et al. Fatores Sociais Determinantes da Reincidência Criminal no Brasil - 0 Caso de Minas Gerais. Pontifícia Universidade Católica de Minas Gerais (PUC-Minas), Belo Horizonte. 2017.Pág. 9.

SILVA, Auricélia Costa de Aguiar. Perfil da Reincidência da Violência Domestica contra a Mulher no Município de Santarém. Monografia. Universidade Federal do Pará. Belém/PA. 2015.2 Disponível em < http://dspace.sti.ufcg.edu.br:8080/jspui/handle/riufcg/11296?mode=full Acessado em: 28 Abr. 2021.

SIMMEL, G. Questões fundamentais da sociologia. Rio de Janeiro: Jorge Zahar Editor, 2006. Pág. 38.

SOUZA, Beatriz Pigossi. Violência doméstica - Lei "Maria da Penha": Solução ou mais uma medida paliativa? Presidente Prudente, SP, 2008. 62 f. (Trabalho de conclusão de curso). Faculdade de Direito de Presidente Prudente "Faculdades Integradas Antônio Eufrásio de Toledo". Pág. 114.

SOUZA, Jessé. Ralé brasileira: quem é e como vive. Horizonte: Editora UFMG, 2009. Pág. 342.

SOUZA, João Paulo Aguiar Sampaio; FONSECA, Tiago. A aplicação da Lei 9.099/1995 nos casos de violência doméstica contra a mulher. Boletim do IBCCrim, n. 168, 2006. Pág. 56.

SAFFIOTI, H.I.B. No fio da navalha: violência contra crianças e adolescentes no Brasil atual. In: MADEIRA, F.R (Org.). Quem mandou nascer mulher? Estudos sobre crianças e adolescentes no Brasil. Rio de Janeiro: Record/Rosa dos Tempos, 1997. Pág. 139. 
TELES, Maria Amélia de Almeida; MELO, Mônica de. O que é violência contra a mulher. São Paulo: Brasiliense, 2002. Pág. 92.

Enviado: Julho, 2021.

Aprovado: Dezembro, 2021. 